\title{
Paracyanogen Reexamined
}

\author{
LEON MAYA \\ Chemistry Division, Oak Ridge National Laboratory, P.O. Box 2008, Oak Ridge, Tennessee 37831-6119
}

\begin{abstract}
SYNOPSIS
Samples of paracyanogen were prepared by the pyrolysis of silver cyanide, the photolysis of cyanogen, and by sputtering a carbon electrode in a nitrogen plasma. This work was undertaken to establish whether these materials are alike and to derive structural information on the basis of FT-IR, ${ }^{13} \mathrm{C}-\mathrm{MAS}-\mathrm{NMR}$, and through temperature-programmed thermal decomposition. Paracyanogen derived from the above sources is indeed alike spectrally and thermally. Paracyanogen is a polymer that incorporates carbon, mostly $\mathbf{s p}^{2}$, and nitrogen in a disordered structure. Cyanogen is the main volatile component released in the thermal decomposition of paracyanogen. The cyanogen released was identified by FTIR and MS. The rate of release reaches a maximum at ca. $700^{\circ} \mathrm{C}$. Paracyanogen is not an appropriate carbon nitride precursor because of its limited thermal stability. (c) $1993 \mathrm{John}$ Wiley \& Sons, Inc.

Keywords: paracyanogen $\bullet$ structure $\bullet$ stability $\bullet$ preparation $\bullet$ polyacyanogen $\bullet$ carbon nitride
\end{abstract}

\section{INTRODUCTION}

Paracyanogen, a polymer of cyanogen, $(\mathrm{CN})_{2}$, is one of the earliest synthetic polymeric materials. It was observed by Gay-Lussac in 1816 during experiments on the pyrolysis of mercuric cyanide. A critical review of significant literature on the properties and structure of CN polymers is given by Labes. ${ }^{1}$ Evidently there are two distinct polymers: one, polycyanogen, is apparently a polymer with a backbone of $-\mathrm{C}=\mathrm{N}-$ units with a pendant nitrile on the carbon. Polycyanogen is produced by the action of alkyllithium derivatives, ${ }^{2}$ by electropolymerization, ${ }^{3}$ and by the reaction of ICN and KCN. ${ }^{4}$ Polycyanogen is electrically insulating, can be drawn into fibers, and produces conducting carbonaceous materials upon pyrolysis. ${ }^{1}$ The infrared spectrum of polycyanogen shows prominent $\mathrm{CN}$ stretching vibrations around $2200 \mathrm{~cm}^{-1}$. Paracyanogen, on the other hand, is an intractable polymer obtained through the pyrolysis of oxamide, silver cyanide, or mercuric cyanide. ${ }^{5}$ Sputtering of carbon in a nitrogen plasma was reported ${ }^{6}$ to produce "paracyanogen-like" films. These films may have technological importance be-

Journal of Polymer Science: Part A: Polymer Chemistry, Vol. 31, 2595-2600 (1993) (C) 1993 John Wiley \& Sons, Inc. cause of their dielectric properties. In addition to these, UV photolysis of cyanogen is also assumed to produce paracyanogen ${ }^{7,8}$ but this is difficult to establish since no IR spectra or chemical properties of the polymer were reported. Paracyanogen shows a prominent band in the IR at ca. $1500 \mathrm{~cm}^{-1}$ (assigned to $\mathrm{C}=\mathrm{N}$ stretching vibrations) and weak $2200 \mathrm{~cm}^{-1}$ bands. Pyrolysis of paracyanogen in the absence of air produces depolymerization and release of cyanogen. The assumed structure of paracyanogen is:<smiles>C=Nc1nc2nc3nc4nc(=C)c(=C)nc4nc3nc2nc1N=C</smiles>

There is little evidence for this ladder structure other than the observation of a tendency of paracyanogen to form filaments. ${ }^{5}$ In addition to this, calculations ${ }^{9}$ indicate metallic conduction for the above structure but the material is insulating.

The present study was undertaken to clarify whether the films obtained by carbon sputtering or material obtained by UV irradiation are indeed paracyanogen and to throw some light on the structure of paracyanogen as derived by ${ }^{13} \mathrm{C}-\mathrm{MAS}-\mathrm{NMR}$, FT-IR, and observations on the thermal behavior 
of this material. An additional goal was aimed at establishing whether paracyanogen would be a precursor for carbon nitride, $\mathrm{C}_{3} \mathrm{~N}_{4}$.

Paracyanogen obtained by the pyrolysis of silver cyanide ${ }^{5}$ was used as reference for comparison with materials obtained by other means.

\section{EXPERIMENTAL}

\section{Paracyanogen: Chemical Preparation}

Paracyanogen was prepared following the procedure described by Bircumshaw et al. ${ }^{5}$ Silver cyanide (Aldrich), about $5 \mathrm{~g}$ portions, were sealed under vacuum in quartz ampoules $(12.7 \mathrm{~mm}$ o.d., $10 \mathrm{~cm}$ in length, and provided with a $6.3 \mathrm{~mm}$ o.d. stem a few centimeters long). The experiments were conducted in a hood with the ampoule contained in a closed nickel tube vented through a column of liquid bleach solution (sodium hypochlorite). CAUTION: Considerable pressures are developed in the course of the pyrolyses with potential release of cyanogen which is toxic. Successful preparations were conducted by a thermal treatment consisting of $2 \mathrm{~h}$ from RT to $300^{\circ} \mathrm{C}, 2 \mathrm{~h}$ at $300^{\circ} \mathrm{C}, 2 \mathrm{~h}$ to $440^{\circ} \mathrm{C}$, and $24 \mathrm{~h}$ at $440^{\circ} \mathrm{C}$. This thermal treatment was selected after observing an ampoule burst shortly before arriving at $440^{\circ} \mathrm{C}$ on a straight $3 \mathrm{~h}$ ramp without the $300^{\circ} \mathrm{C}$ soak period. The ampoules were opened into a vacuum line and yielded small amounts of cyanogen. Cyanide conversion into a nonvolatile polymer (paracyanogen yield) was ca. 93\%. The residues from the pyrolysis were subjected to acid washing to remove the silver, and subsequently dried under dynamic vacuum for $3 \mathrm{~h}$ at $300^{\circ} \mathrm{C}$.

\section{Sputtering}

Films, a few microns thick, were deposited on silicon wafers in a glow discharge system by sputtering a graphite electrode (graph-foil) $11.3 \mathrm{~cm}^{2}$ in area in a nitrogen plasma which was generated typically by a potential drop of $600 \mathrm{~V}$ while passing a current of $20 \mathrm{~mA}$ (a power density of $0.5 \mathrm{~W} / \mathrm{cm}^{2}$ ). The system was held at a pressure of $0.4 \mathrm{kPa}$ while maintaining a flow of $20 \mathrm{~mL} / \mathrm{min}$ of high purity nitrogen. Typical deposition times were 2-4 h. The amount deposited was established by the gain in weight of the wafer.

\section{Photochemistry}

Very small amounts, $<0.1 \mathrm{mg}$, of a brown film were deposited on $13 \mathrm{~mm}$ o.d. quartz ampules filled with cyanogen to a pressure of 1-2 atm and exposed to a $5 \mathrm{~mm}$ beam, from a deuterium lamp. (A mercury vapor lamp is inadequate since irradiation at wave lengths lower than $220 \mathrm{~nm}$ is required. ${ }^{7}$ ) Irradiation times ranged between 3-6 days at a power level of about $30 \mathrm{~W}$. The ampoules were opened into a vacuum line to recover unreacted cyanogen. The residue remaining in the ampoule was removed by rubbing with solid $\mathrm{KBr}$. The $\mathrm{KBr}$ was then pressed into a pellet to obtain an IR spectrum.

\section{Characterization}

Infrared spectra were obtained in a Bio Rad Model FTS 60 FTIR spectrophotometer. Temperatureprogrammed thermal decomposition (TPTD) experiments were conducted in a system consisting of a tube furnace controlled to heat a quartz tube containing the specimen at $10^{\circ} \mathrm{C} / \mathrm{min}$. The system was swept with high-purity helium and the effluent was monitored with a Hewlett-Packard Model 5970 mass analyzer. Solid-state ${ }^{13} \mathrm{C}$-NMR were obtained on a Bruker MSL spectrometer operating at 2.35 $\mathrm{T}$. The ${ }^{13} \mathrm{C}$ signal was generated using a $5.0 \mu \mathrm{s} 90^{\circ}$ pulse.

\section{RESULTS AND DISCUSSION}

\section{Synthesis}

Two batches of paracyanogen were prepared by the pyrolysis of silver cyanide. The purification process to remove silver proved to be difficult (Bircumshaw et al. ${ }^{5}$ make no mention of difficulties in their description, although the quantitative analyses of their paracyanogen were on products derived from oxamide and mecuric cyanide.) In one case, removal of the silver was made by stirring with $8 M \mathrm{HNO}_{3}$ through a $30 \mathrm{~h}$ period. This removed about $65 \%$ of the initial silver and left a product containing 59.1 wt $\% \mathrm{Ag}$ (product A). The second batch was stirred for 10 days with $12 \mathrm{MHNO}_{3}$. In this case about $85 \%$ of the initial silver was removed to yield a product containing $38.3 \mathrm{wt} \% \mathrm{Ag}$ (product B). Apparently the silver particles produced in the pyrolysis are very well coated by the polymer and thus inaccessible for dissolution. The presence of metallic silver as an independent phase in the products was confirmed by the $x$-ray powder diffraction pattern of the materials. Furthermore, metallic silver is recovered quantitatively from the thermal treatment of products $A$ and $B$ (to be discussed in another section). Another interesting aspect of the chemical preparation is the fact that small amounts of cyanic acid, 
HOCN, and its trimer (cyanuric acid) are evolved during the vacuum drying of the products. Evidently these volatile products are the result of chemical attack of paracyanogen by the acid treatment.

The sputtered films were pale yellow and the residues from the photochemistry appeared as yellowbrown films and fine dust settling at the bottom of the ampoules.

\section{Vibrational Spectroscopy}

The infrared spectrum of product $A$ is given in Figure 1 along with spectra of a sputtered film on silicon and that of the photochemical residue. Also given, for comparison purposes, is a spectrum of polyacrylonitrile (PAN). It is seen that, other than that of PAN, there is a resemblance among the spectra showing a weak band for triple bonded $\mathrm{CN}$ at about $2200 \mathrm{~cm}^{-1}$ and strong broad band for double bonded $\mathrm{CN}$ at about $1500 \mathrm{~cm}^{-1}$, thus suggesting structural similarity among all these materials obtained by different means. The $2200 \mathrm{~cm}^{-1}$ band in the photochemical product is more intense, perhaps due to the fact that shorter polymeric units are formed in that process. Presumably shorter polymers would have a relatively higher proportion of terminal CN moieties. The sputtered film obtained in the course of this study seems to differ from that described by Cuomo et $a .^{6}{ }^{6}$ who only mentioned bands in the $2200-2350 \mathrm{~cm}^{-1}$ regions.

The sputtered films obtained in the course of our study are inert, changing little after exposure to air.
However, after longer periods (months), subtle changes appear. This is illustrated in Figure 2 which shows spectra of the same film taken 3 months apart. Also shown is the difference spectrum obtained by subtraction of the spectra of initial film from the film exposed to air. As evidenced by the appearance of bands at $3331,3198,1684$ (shoulder), 1633, and $1453 \mathrm{~cm}^{-1}$, the film was partially hydrolyzed. It appears that water adds across the $\mathrm{C}=\mathrm{N}$ moiety to generate a hydroxyl amine. The presence of the 1684 $\mathrm{cm}^{-1}$ band suggests hydrolysis of the $\mathrm{C}=\mathrm{N}$ moiety to generate an amide function.

Raman spectra were obtained for products A and $B$ derived from the chemical preparation. The spectra showed the typical pair of bands observed for carbonaceous materials. ${ }^{10,11}$ However, as in the case of a recent study, ${ }^{12}$ the $\mathrm{E}_{2} \mathrm{~g}$ band was considerably displaced from the typical $1590 \mathrm{~cm}^{-1}$ to ca. 1510 $\mathrm{cm}^{-1}$. Apparently this is due to the incorporation of nitrogen into the graphitic layers. This fact can be considered in an attempt to derive a reasonable structure for the polymer.

\section{Temperature-Programmed Pyrolyses}

A series of pyrolysis experiments was conducted. Products A and B from the chemical preparation and coated silicon wafers were subjected to temperature-programmed thermal decomposition (TPTD). The profile of the mass analyzer response as a function of temperature for product $A$ is given in Figure 3. The thermal decomposition proceeds in a single

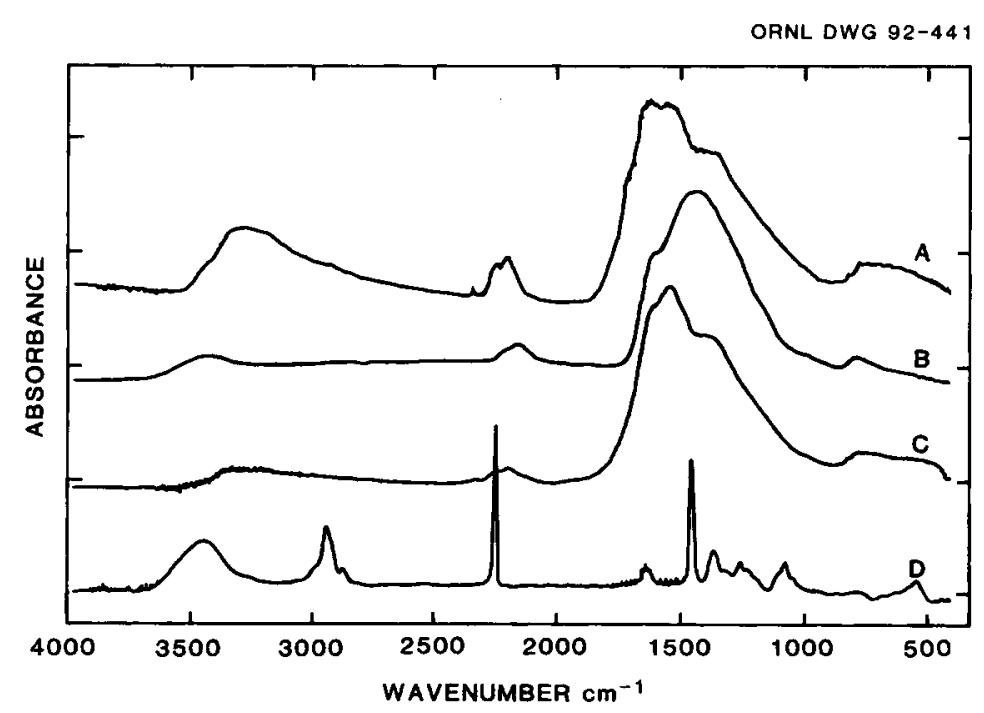

Figure 1. Infrared spectra of: (A) photochemical product dispersed in $\mathrm{KBr},(\mathrm{B})$ chemical product derived from $\mathrm{AgCN}$, (C) sputtered product on silicon wafer, (D) polyacrylonitrile in $\mathrm{KBr}$ pellet. 


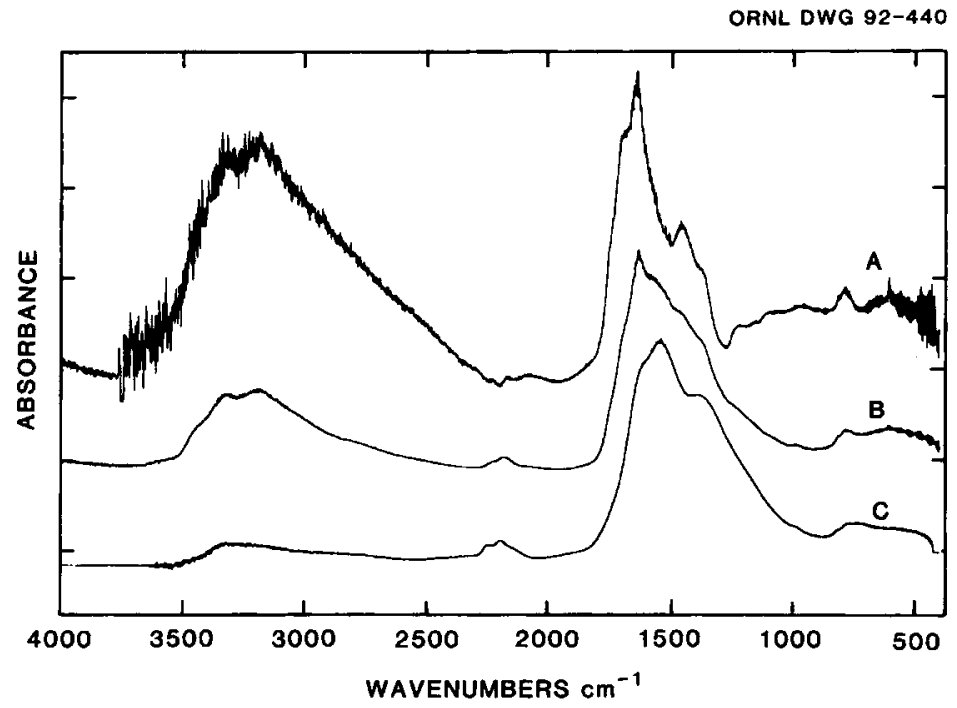

Figure 2. Infrared spectra of: (A) difference (B-C), (B) paracyanogen film on silicon after 3 months exposure to air, (C) freshly sputtered film of paracyanogen on silicon.

event that reaches a maximum at $695^{\circ} \mathrm{C}$. Volatile evolution is almost exclusively accounted for by cyanogen identified by the MS response and independently by the IR of the volatile fraction produced in the pyrolysis. There were small contributions $(<$ $1 \%$ ) due to cyanic acid, HOCN, and hydrogen cyanide identified with the small shoulder on the low temperature side of the peak. The TPTD profiles for product $B$ and the coated wafer also peaked at $695^{\circ} \mathrm{C}$. However, in these samples the presence of the acids was somewhat more pronounced (a few percent) apparently due to the longer silver dissolution treatment for product $B$ and some hydrolysis of the coating. These results are similar to those of Cuomo et al., ${ }^{6}$ who observed peak cyanogen evolution at $675^{\circ} \mathrm{C}$.
Material balances around the thermal treatment showed that all of the coating deposited by sputtering was volatilized and identified as cyanogen. Similarly, volatiles evolved from the paracyanogen samples leave pure metallic silver as residue as quantified by chemical analysis; thus the chemical composition is established as silver, 59.1 and $38.3 \mathrm{wt} \%$, for samples $A$ and $B$, respectively, and the balance being paracyanogen in both cases.

\section{High-Pressure Pyrolysis}

A high-pressure pyrolysis experiment was conducted to assess whether paracyanogen would be a suitable precursor to carbon nitride, $\mathrm{C}_{3} \mathrm{~N}_{4}$, a hypothetical material predicted ${ }^{13}$ to have a hardness comparable

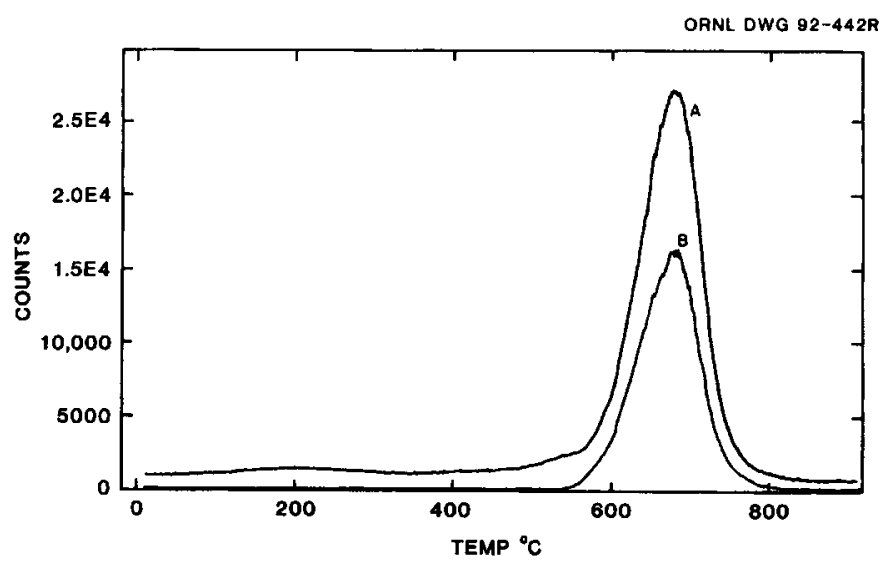

Figure 3. Mass analyzer response: (A) profile of total ion current versus temperature in the decomposition of paracyanogen derived from silver cyanide (product A), (B) ion of mass 52. 
to diamond. Earlier attempts on our part ${ }^{12}$ to produce $\mathrm{C}_{3} \mathrm{~N}_{4}$ lead to the incorporation of nitrogen on pyrolytic residues, but the carbon remained $\mathrm{sp}^{2}$ hybridized instead of $\mathrm{sp}^{3}$ as expected for the predicted $\mathrm{C}_{3} \mathrm{~N}_{4}$ structure. Platinum capsules loaded with products $\mathrm{A}$ and $\mathrm{B}$ were subjected to $0.3 \mathrm{GPa}$ hydrostatic pressure at $725^{\circ} \mathrm{C}$ for $75 \mathrm{~h}$. The internal pressure in the capsule containing product $\mathrm{B}$ exceeded the external pressure. The other capsule did not leak and was found, upon opening into a vacuum line, to contain all the initial nitrogen in the form of molecular nitrogen, thus showing that paracyanogen is not an appropriate precursor. The residue consisted of metallic silver and graphitic carbon. It is interesting to note the difference in the course of the pyrolysis of paracyanogen in an open system to release cyanogen with the pyrolysis in a closed system which led to cyanogen decomposition. The difference might well be due to the presence of silver in the products examined.

\section{${ }^{13}$ C-MAS-NMR}

Solid-state ${ }^{13} \mathrm{C}$-NMR spectra were obtained using a one-pulse acquisition experiment employing a $5 \mu \mathrm{s}$ $90^{\circ 13} \mathrm{C}$ radio frequency pulse. The data were recorded with 5 and $60 \mathrm{~s}$ recycle delays and produced spectra of similar signal-to-noise ratio. An estimate of the carbon $T_{1}$ of 1-2 s that follows from this result indicates an efficient relaxation mode, one likely to involve the free radical spin density of the sample. The spectrum of product $\mathrm{B}$, obtained using a $60 \mathrm{~s}$ recycle, is shown in Figure 4. It consists of a broad asymmetric resonance which peaks at $153 \pm 5 \mathrm{ppm}$ and is consistent with $\mathrm{sp}^{2}$ carbon substituted with nitrogen. The uncertainty in peak chemical shift results from the uncertain phasing criteria in such broad line spectra. The asymmetry of the main peak suggests the presence of a weak band in the 110$120 \mathrm{ppm}$ range possibly due to the contribution of terminal sp ${ }^{1} \mathrm{CN}$ which would be consistent with the weak $\mathrm{CN}$ band in the IR. No interference was detected due to the presence of silver. Apparently the metal is finely divided and well coated.

\section{Structural Considerations}

Whangbo et al. ${ }^{9}$ considered the following structures in their discussion of the properties and energetics of conjugated and two-dimensional polymers:

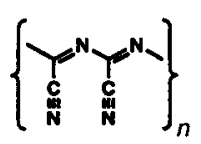

1

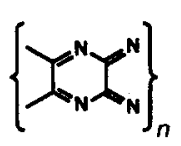

2

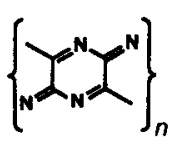

3

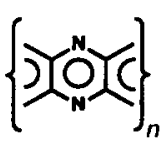

4 the relative stabilities of $1,2,3$ and 4 are in $\mathrm{kJ} /$ mol $0,39.3,52.7$, and 124.3. The aromatic configuration 4 is the least stable. The electrical conductivity of the ladder configurations is likely to be metallic. $^{9}$

Examination of the above structures in the light of the findings of the present study indicates that none adequately describes paracyanogen. The linear structure 1 with pendant nitrile moieties is readily excluded on the basis of the IR since the nitrile intensity, $2200 \mathrm{~cm}^{-1}$ region, in paracyanogen is relatively weak. See, in contrast, the spectrum of polyacrylonitrile in Figure 1. Additionally, the intensity of the $\mathrm{sp}^{1}$ type carbon in the ${ }^{13} \mathrm{C}$-NMR is much weaker than that of the $\mathrm{sp}^{2}$ carbon. The ladder structures are excluded because of the electrical conductivity argument. Furthermore, a sharper NMR spectrum could be expected for ordered struc-

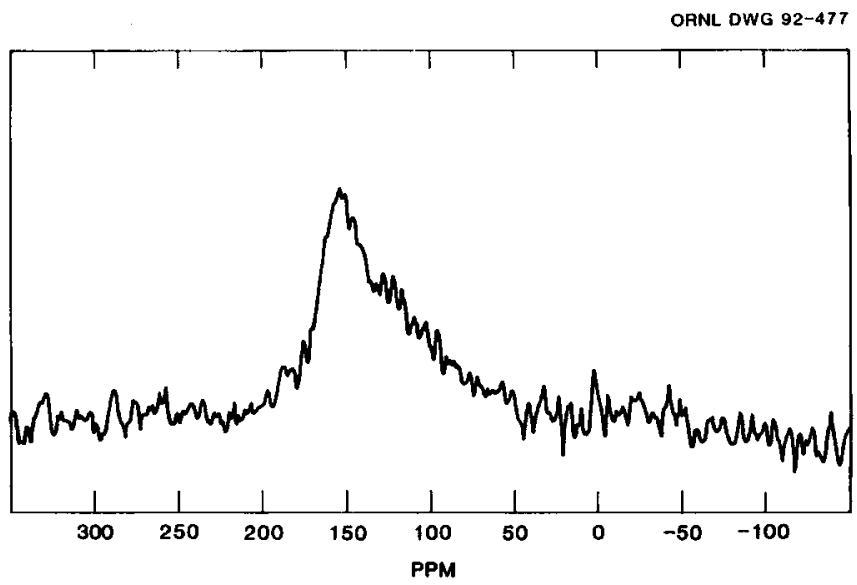

Figure 4. ${ }^{13} \mathrm{C}-\mathrm{MAS}-\mathrm{NMR}$ of paracyanogen (product B). 
tures such as 2,3 , and 4 . Having excluded the above structures, one confronts the fact that paracyanogen reverts to the monomer, so it is likely that structural unit is present. The IR and NMR strongly indicates the presence of $\mathrm{sp}^{2}$ carbon in the form of $\mathrm{C}=\mathrm{N}-$ moieties. The Raman spectrum also indicates a graphitic system that incorporates nitrogen. However, unlike graphite, it does not seem to have a delocalized pi electron system. On the basis of all the above arguments the following disordered structure, initially considered by Brotherton and Lynn, ${ }^{14}$ is offered as a possible representation of paracyanogen:<smiles>CN=C(C)C(C)=NC(=NC)C(N=C(C)C(C)=NC)=NC(C#N)=NC(=NC)C(C)=NC</smiles>

\section{CONCLUSIONS}

The similarities in the IR spectra of paracyanogen obtained by photochemical, chemical, and through sputtering graphite in a nitrogen plasma strongly suggest that these materials are essentially the same. This is reinforced by the commonality in the thermal behavior of the chemical and sputtered products.

The structure of paracyanogen is mainly made of $\mathrm{sp}^{2}$ carbon in a disordered structure incorporating nitrogen but without an extended delocalized $\pi$ electron system but which however can form isolated domains of conjugation. The limited thermal stability of paracyanogen precludes its use as a precursor of carbon nitride.
Research sponsored by the Division of Materials Sciences, Office of Basic Energy Sciences, U.S. Department of Energy under Contract DE-AC05-84OR21400 with Martin Marietta Energy Systems, Inc.

The author is grateful to D. R. Cole for performing the high-pressure pyrolysis, G. M. Begun and E. W. Hagaman for obtaining Raman and NMR spectra, respectively, and also to G. M. Brown, R. A. Sachleben, and M. E. Sigman for assistance and helpful discussions.

\section{REFERENCES AND NOTES}

1. M. M. Labes, Mol. Cryst. Liq. Cryst., 171, 243 (1989).

2. J. Peska, M. J. Benes, and O. Wichterle, Collect. Czech. Chem. Commun., 31, 243 (1966).

3. J. H. Chen and M. M. Labes, J. Polym. Sci. Polym. Chem. Ed., 23, 517 (1985).

4. Z. Toth, J. Gulyas, and M. T. Beck, Inorg. Chim. Acta, 113, 67 (1986).

5. L. L. Bircumshaw, F. M. Tayler, and D. H. Whiffen, J. Chem. Soc., 931 (1954).

6. J. J. Cuomo, P. A. Leary, D. Yu, W. Reuter, and M. Frisch, J. Vac. Sci. Technol., 16, 299 (1979).

7. T. R. Hogness and Liu-Sheng Ts'ai, J. Am. Chem. Soc., 54, 123 (1932).

8. M. E. Fabian, J. Mater. Sci., 2, 424 (1967).

9. M. H. Whangbo, R. Hoffman, and R. B. Woodward, Proc. R. Soc. Lond., A366, 23 (1976).

10. F. Tunistra and J. L. Koenig, J. Chem. Phys, 53, 1126.(1970).

11. C. Beny-Bassez and J. N. Rouzaud, Scanning Electron Microsc., 1, 119 (1985).

12. L. Maya, D. R. Cole and E. W. Hagaman, J. Am. Ceram. Soc., 74, 1686 (1991).

13. A. Y. Liu and M. L. Cohen, Science, 245, 841 (1989).

14. T. K. Brotherton and J. W. Lynn, Chem. Rev., 59, 841 (1959).

Received September 22, 1992

Accepted February 20, 1993 